\title{
Effect of Density and Pointed Corner Degree of Pore on Local Stress in Welded Structures: Defect in Marine Structures
}

\author{
Farida Bouafia, ${ }^{1,2}$ Boualem Serier, ${ }^{1}$ Nassim Serier, ${ }^{1}$ and Sardar Sikandar Hayat ${ }^{3}$ \\ ${ }^{1}$ LMPM, Mechanical Engineering Department, University of Sidi Bel Abbes, 22000 Sidi Bel Abbes, Algeria \\ ${ }^{2}$ Institute of Science and Technology, University of Ain Temouchent, BP 284 RP, 46000 Ain Temouchent, Algeria \\ ${ }^{3}$ Department of Physics, Hazara University, Mansehra 21300, Pakistan \\ Correspondence should be addressed to Farida Bouafia; fbouafia2011@yahoo.fr
}

Received 30 July 2013; Accepted 23 October 2013; Published 16 January 2014

Academic Editors: N. Anifantis, R. Brighenti, and S. Cartmell

Copyright (C) 2014 Farida Bouafia et al. This is an open access article distributed under the Creative Commons Attribution License, which permits unrestricted use, distribution, and reproduction in any medium, provided the original work is properly cited.

\begin{abstract}
The process of assembly by welding, in marine structures, led to the creation of microstructural heterogeneities zones. Welded structures generally contain defects such as lack of penetration, slag inclusion, porosity, and misalignment. Generally these zones can be discontinuities geometrical. At the origins of stress concentration, these regions are favourable sites where fatigue cracks can initiate and propagate. In this study, the 3D finite element method is used to analyze the distribution of stress (strain) generated by the presence in the weld nugget of a pore formed during the welding process. This analysis was made in the matrix-pore interface. The effects of density and pointed corner degree of pore on the stress levels were also analyzed.
\end{abstract}

\section{Introduction}

The major weld imperfections, in marine structures, include porosity, lack of penetration, lack of fusion, slag inclusion, undercut, misalignment, and so forth [1]. The size and frequency of imperfection depend on the welding process, weld procedure, geometry of weldment including ease of access for welding, and the care exercised in making the weld. These imperfections have different characteristics and, in most cases, are difficult and costly to detect and define nondestructively.

These weld defects can significantly influence the local stress field in the vicinity of welds when the welded component is subjected to cyclic fatigue load. In most cases, weld defects lead to severe stress concentration and thus accelerate fatigue crack growth. In agreement with many authors, fatigue and fracture are the most critical failure mode of welded joints [2-4]. Hence, it is up of importance to study the stress distribution around these zones.

This behavior is attributed to the fact that for a given fatigue life, a much larger embedded imperfection can be tolerated than a surface imperfections [5]. Different welds imperfections as described by Maddox [1] are shown in Figure 1.
Porosity is defined as cavity type discontinuities (voids) formed by gas entrapment during solidification. The shape of the void is dependent on the relative rates of solidification of the weld metal and the nucleation of the entrapped gas. The resultant stress field surrounding the pore depends upon the pore shape and the loading.

Porosity, though generally spherical in shape, can assume many shapes and configurations. These include elongated pores, rows of single pore or collinear pores, and pore clusters. Determining the effects of various sizes and shapes of pores is an important factor affecting the structural integrity of weldments.

Fatigue cracks generally initiate at a geometrical discontinuity such as a notch or pore. These act as stress concentrations, raising the stress in the region of the notch to levels above the nominal stresses. The material at the notch root may deform plastically while the rest of the component remains essentially elastic. Subjecting the region to cyclic loading resulting in plastic deformation will eventually result in a fatigue crack.

Fatigue crack propagation in marine structures is obviously governed by the mechanics of considerably different four types of multiscale problems. Problems of structural 


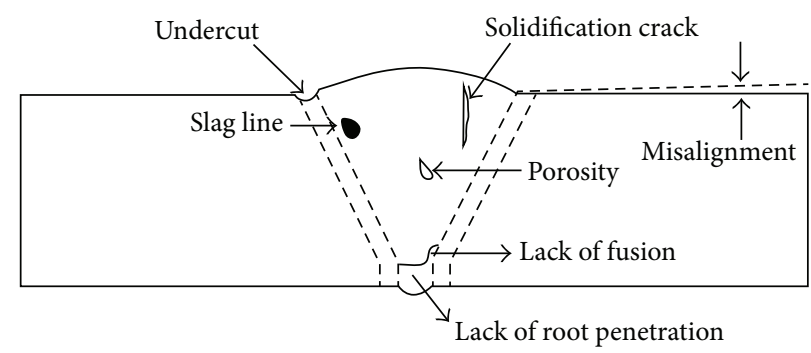

FIGURE 1: Different weld imperfections in a butt-joint [1].

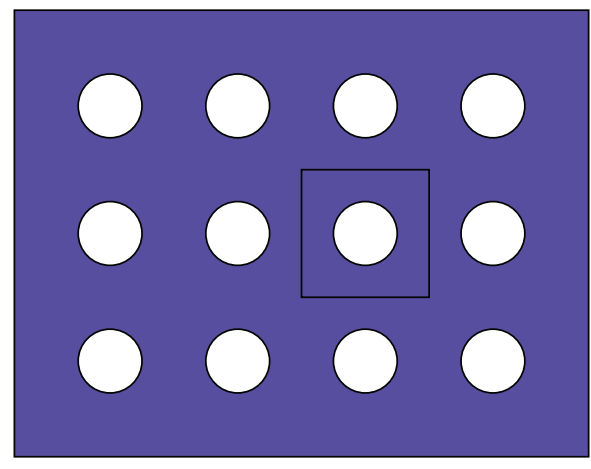

(a)

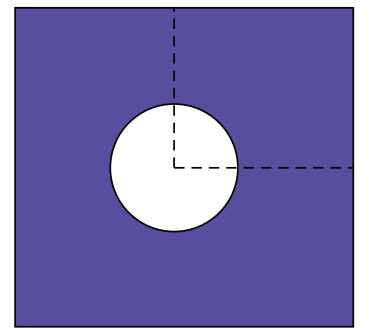

(b)

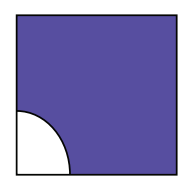

(c)

FIGURE 2: (a) Square packing of pores within the matrix and the square periodic unit cell. (b) Unit cell, (c) quarter of unit cell.

response to environmental loads have a length scale of several hundred meters, whereas the possible detectable size of cracks from initial defects in a weld is of the order of millimeters [6].

Many of the researchers have studied the welding defects [7-9]. Bouafia et al. [9] utilizes a numerical analysis for the computation of stress concentration factor generated by the presence in the weld nugget of a pore formed during the welding process. Welded structure containing porosity is subjected to uniaxial tensile stress. The effects of geometrical parameters of the pore and the interaction pore-defect on the stress concentration factor variation have been analyzed by [9].

In this study, a finite element model is developed to analyze numerically the distribution of local stresses generated by the presence of a pore formed during the welding process. The analysis has been extended to the effect of density and pointed corner degree of pore on the stress levels.

Through this study, we show that the formation of porosity due welding process can weaken the weld by notch effect. In the real case air bubbles or moisture trapped during welding may lead to the formation of porosity.

\section{Finite Element Model}

The distribution of the pores in the matrix was modeled using unit cells in which the pores are placed perfectly uniformly within the matrix and unit cells containing large numbers of randomly spaced pores (Figure 2(a)). For the unit cells with the uniformly spaced pore arrangement, the pores were packed in a square array as shown in Figure 2(b). This packing is the most common arrangement used in many socalled "unit cell" analyses [9]. In addition to the uniformly spaced pore arrangements in Figure 2, numerical simulations were conducted in this work using repeating square cells of the matrix which contained pore. In this investigation, a three-dimensional finite element analysis was developed. For reasons of symmetry in geometry, we studied a quarter of the complete model (Figure 2(c)) in order to reduce the calculation time. Hence, the boundary conditions, must be such that the symmetry is retained, that is, all the nodes at the faces of symmetries are constrained to have a null normal displacement (Figure 3(a)), all other boundaries were free [9]. The structure was subjected to a tensile mechanical load (Figure 3(b)). The choice of tensile stresses in the welded joint subjected is justified by the analysis of the mechanical behavior in open mode (mode 1), the most dangerous mode. During commissioning of the seal, the stresses are highly concentrated in the vicinity of this very close porosity. The initiation of the crack from a pore may be considered at the moment when the seal reaches a level of damage. After this level, this joint begins to undergo a softening behavior and gradually loses its rigidity.

The porosity is located in the center of the weld nugget and simulated as a hole with a diameter $\varphi$ of $50 \mu \mathrm{m}$, characterizing an average size selected from the literature [9]. The matrix is considered as a Steel matrix with a Young modulus $E=205 \mathrm{GPa}$ and a Poisson coefficient $v=0.3$.

The finite-element computations was performed, using commercial FE software package ABAQUS [10]. The precision of numerical computation is strongly related to 


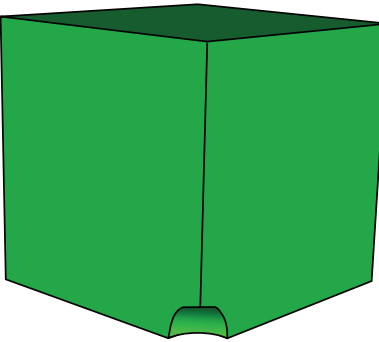

(a)

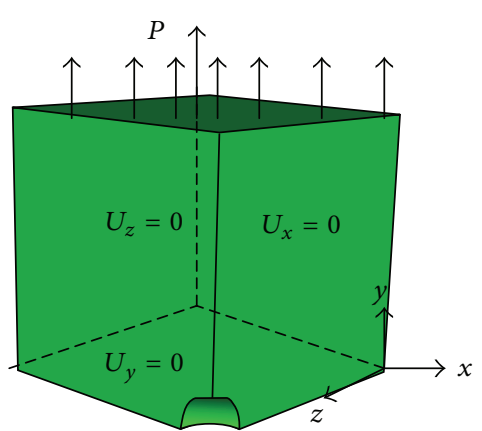

(b)

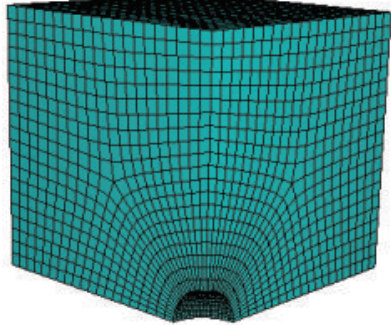

(c)

Figure 3: (a) The three-dimensional finite element models, (b) boundary condition and loading condition, and (c) finite element models mesh.

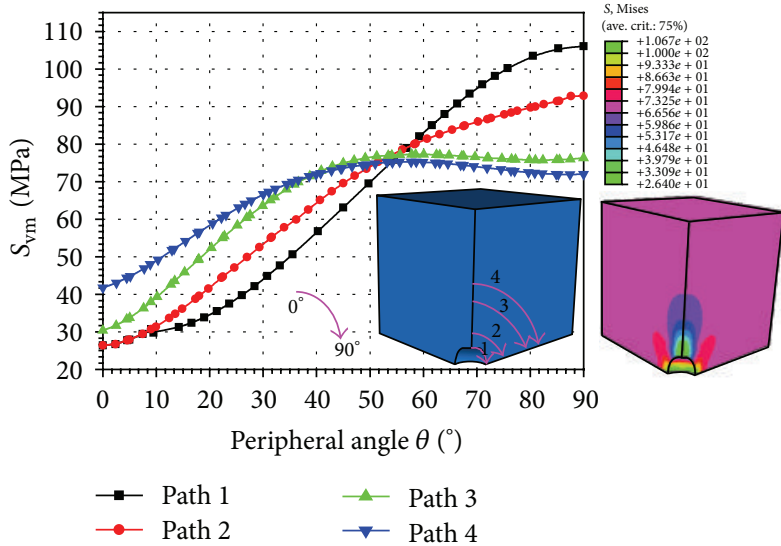

(a)

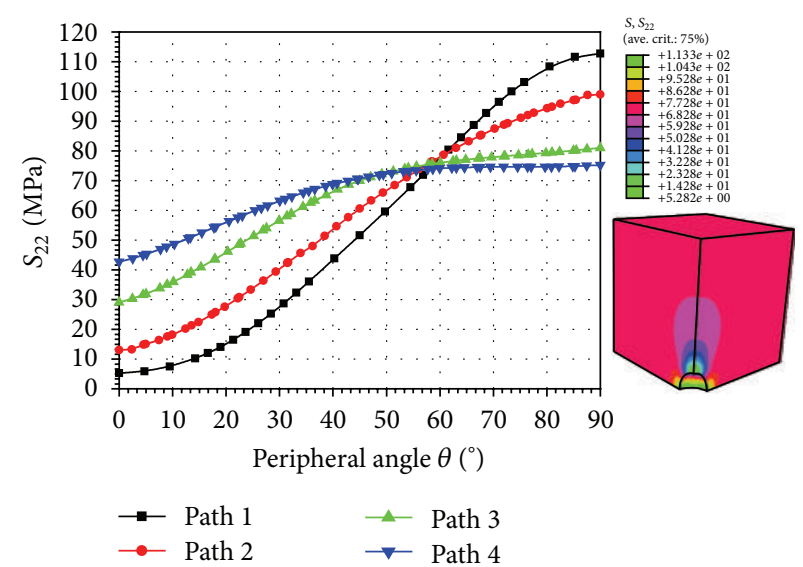

(b)

FIGURE 4: Variation of equivalent and normal stresses according to the peripheral angle $\theta$, for different paths, for $P=70 \mathrm{MPa}$.

the quality of the mesh in the structure. In addition, due to the stress concentrations expected at the matrix-pore interface, the mesh was refined at this zone, A 8-node linear brick (C3D8) finite elements are used for the model (Figure 3(c)). The finite element model is shown in Figure 3(c) with 10000 elements, and it has a fine grid at the matrix-pore interface.

\section{Results and Discussion}

3.1. Stress Analysis. We studied the distribution of the von Mises stress $S_{\mathrm{vm}}$ and normal stress along $y$-axis $S_{22}$ in the matrix and the pore-matrix interface for four different positions of path numbered Path 1, Path 2, Path 3, and Path 4 (Figure 4). This figure shows, respectively, the variation of equivalent and normal stress according to the peripheral angle $\theta$ (peripheral angle $\theta$ is the angle around the pore. It is between $0^{\circ}$ and $90^{\circ}$ ), for different paths. The higher stresses are located at the vicinity of the interface between the matrix and pore. Far from the interface the matrix is completely free of this stress. Indeed, these stresses increase gradually the amplitude from $\theta=0^{\circ}$ to $\theta=90^{\circ}$. These stresses are positive in the matrix and the pore-matrix interface. This clearly shows that the matrix is in tension. These stresses are of greater intensity at the matrix-pore interface (Path 1), and far from the interface, this stress is relaxed. They are the largest in the immediate vicinity of the interface. This stress can constitute a risk of damage to the welding joint.

3.2. Strain Analysis. The stress induced locally in the matrix around the pore lead to the strain of this matrix in the vicinity close to this defect. This strain depends on the amplitude of the stress applied to the structure and thus of the level of the stress generated in the joint of welding close to the pore [9]. Variation of Max principal stress $(S)$ according to the Max principal strain $(E)$, for Path 1 is represented in Figure 5. It shows clearly that the amplitude of Max principal stress grows with the increase in Max principal strain and that the level of this stress and strain reaches its maximum close to the matrix-pore interface. This behavior shows that the pore initially spherical form becomes deformed elastically for tending towards an elliptical form. Under these local pressures the pore tends to become deformed preferentially, according to its axis $x$, towards its center of gravity [9].

3.3. Effect of Pore Density. The pore density is the significant parameter in the analysis of the local stresses in the weld joint. 


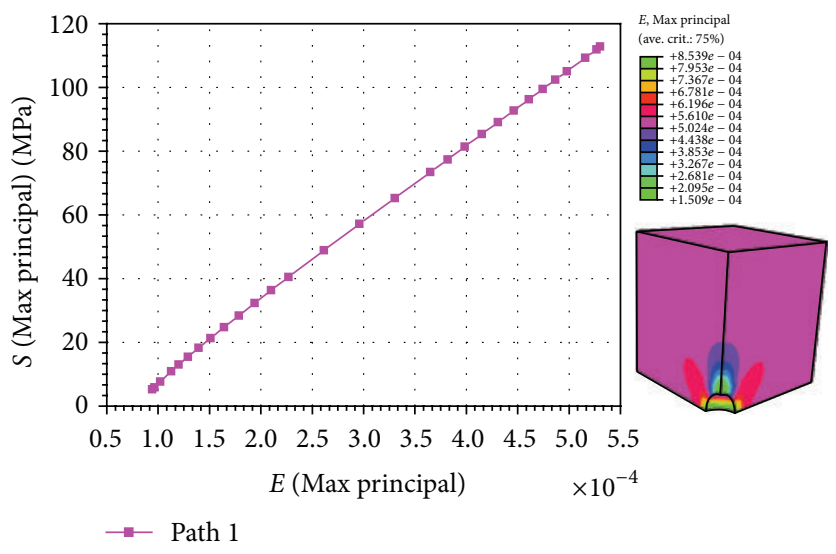

FIgURE 5: Variation of Max principal stress $(S)$ according to the Max principal strain $(E)$, for Path 1, for $P=70 \mathrm{MPa}$.
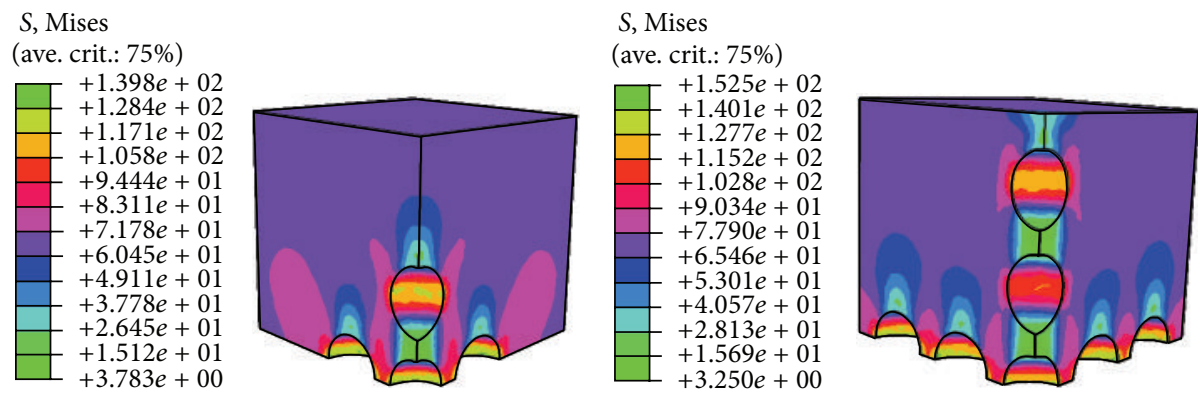

FIGURE 6: Equivalent stress distribution for 4 and 7 porosities, for $P=70 \mathrm{MPa}$.

We will study the effect of 1,4 , and 7 pores on the equivalent and local stresses.

Figure 6 presents the distribution of equivalent stress $S_{\mathrm{vm}}$ in the matrix and pore for two models with 4 and 7 porosities for $P=70 \mathrm{MPa}$. The higher stress is located at the vicinity of the interface between the matrix and pores. Far from the interface, the matrix is completely free of this stress. The equivalent stress leads to traction in the pores and matrix.

In Figure 7, the effect of pore density on the level of the von Mises equivalent stress is represented. It shows clearly that the amplitude of this stress grows with the increase in the pore density to the level of the matrix. A more significant pore density induced stresses of strong intensities at the interface matrix-pore. In addition, $S_{\mathrm{vm}}$ reaches its highest level at $90^{\circ}$.

Figure 8 presents the distribution of normal stress $S_{22}$ in a matrix with 4 and 7 pores for $P=70 \mathrm{MPa}$. The higher stresses are located at the vicinity of the interface between the matrix and pores. The effect of pore density on the level of the normal stress $S_{22}$ is represented in Figure 9. It shows clearly that the intensity of this stress grows with the increase in pore density. The normal stress takes the highest level at the edge of the pore of $\theta=90^{\circ}$.

The effect of the interaction of two pores on the level of the internal stresses induced in the ferritic matrix in the center of the distance between two pores was studied by Bouafia et al. [11]. Figure 10 presents the distribution of this stress and their intensity in the ferritic matrix and two pores for

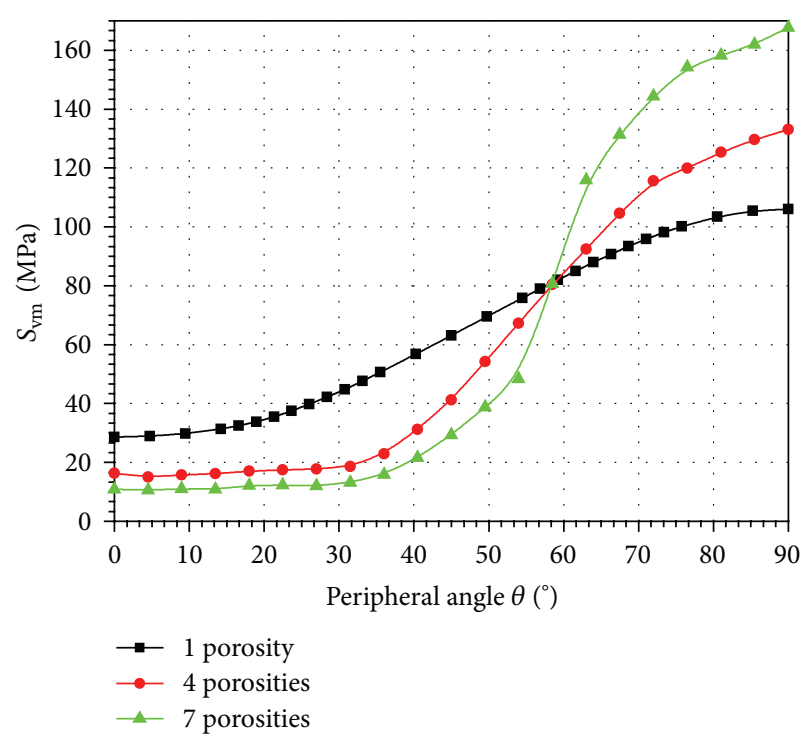

FIGURE 7: Variation of equivalent stress according to the peripheral angle $\theta$, for different pore density, for path 1 and $P=70 \mathrm{MPa}$.

$P=100 \mathrm{MPa}$. The higher stress occurs in the vicinity of the matrix-pore interface. The stress is computed along a distance $d$. The analysis of this figure shows that the stress along axis $Y Y$ in the matrix in the center of the distance between two 

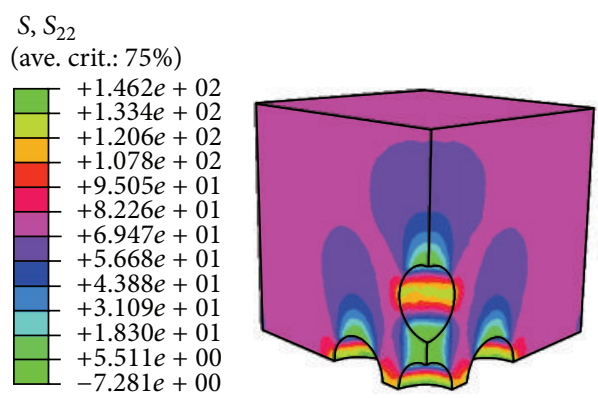

$S, S_{22}$

(ave. crit.: $75 \%$ )

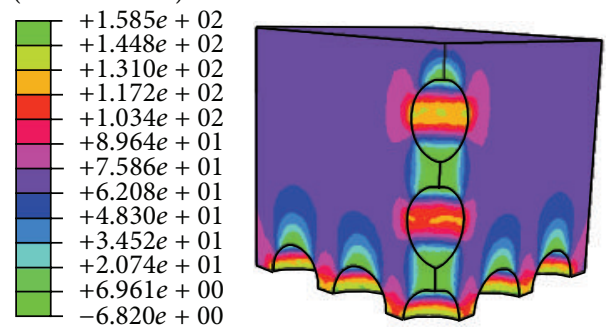

Figure 8: Normal stress distribution for 4 and 7 porosities, for $P=70 \mathrm{MPa}$.

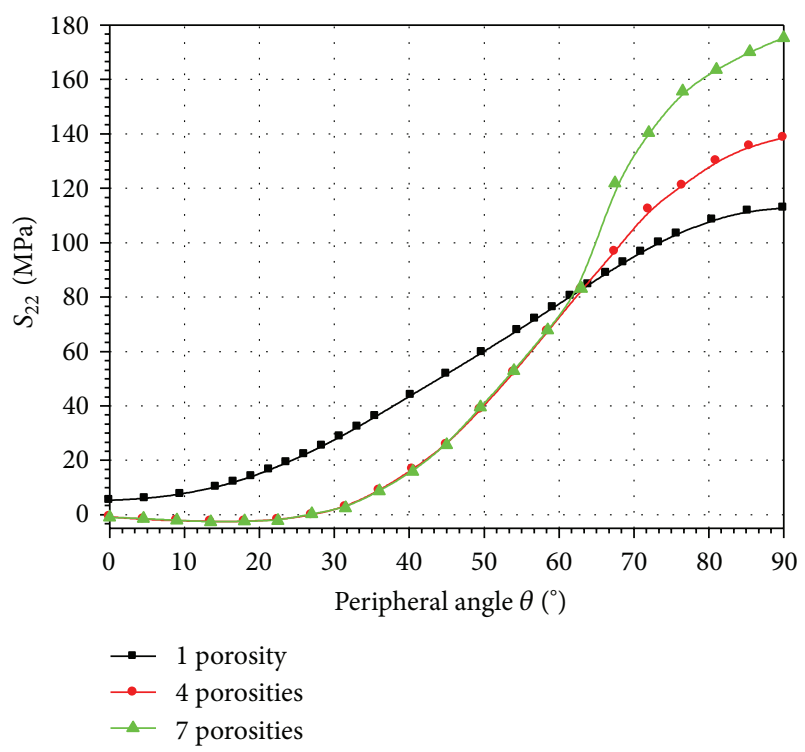

FIGURE 9: Variation of normal stress $S_{22}$ according to the peripheral angle $\theta$, for different pore density, for path 1 and $P=70 \mathrm{MPa}$.

pores increase progressively when the distance between the two pores decreases. This stress is strongly localised in the matrix close to the surface of the pores. The decrease of the distance between pores involves an increase of the stress.

This result shows that an increase of pores density generates a strong stress concentration in the matrix being able to initiate and propagate cracks. This behavior constitutes a damage risk of the weld joint. A very low stresses level does not present any risk of failure of the weld joint [11].

3.4. Effect of Pointed Corner Degree of Pore on Stress and Strain Distributions. In the present study, finite element method was introduced to analyze the equivalent stress and strain fields in five models for different shaped pores (Figure 11). The pointed corner degree of porosity varies from $180^{\circ}$ to $30^{\circ}$. It is supposed that the five pores have equal areas.

Distribution of equivalent stress in the pore-matrix interface varies with the pore shape (Figure 11). As far as the spherical pore is concerned, the equivalent stress distributes uniformly and remains a low level of $106 \mathrm{MPa}$. When the pore becomes angular, there is a stress concentration in the pointed pore corner. With decreasing pointed corner degree of the pore, this concentration increases rapidly and becomes more and more intense. In the shuttle-shaped pore, the maximum equivalent stress exists at the pointed corner and is up to $301 \mathrm{MPa}$ (Figure 12(a)).

In Figure 12(b), it is obvious that the strain near the interface varies with pore shape. When pointed corner degree of pore decreases there is an increasing strain concentration in the matrix around the pointed corner. The maximum strain in the shuttle-shaped pore is much higher than that in the spherical pore where the strain distributes uniformly around the pore (Figure 12(b)).

\section{Conclusions}

The porosity in the steel matrix resulting from a process of welding in marine structures generates normal stress whose level reaches its maximum value with the interface matrix porosity. Far from this interface the matrix is completely released of this stress. These stresses can constitute a risk of damage to the welding joint.

The level and the distribution of the equivalent and normal stress depend on the density of porosity. These stresses are all the stronger as the density of the pore grows. The pore density has a great effect on stress distributions of the matrix-pore model.

The pore shape has a significant influence on the level of the developed stress and strain. The pointed pore corner can result in intense stress concentration in the pointed pore corner and in situ strain concentration in the matrix around the pointed pore corner.

Distribution of strain in pore-matrix interface varies with the pore shape. There is a strain concentration around the pointed corner degree of pore and this concentration increases with decreasing pointed corner degree of pore.

The distribution of stress in the pore also varies with the pore shape. There is a serious stress concentration in the pointed corner of pore and this concentration increases rapidly with decreasing pointed corner degree of pore. 

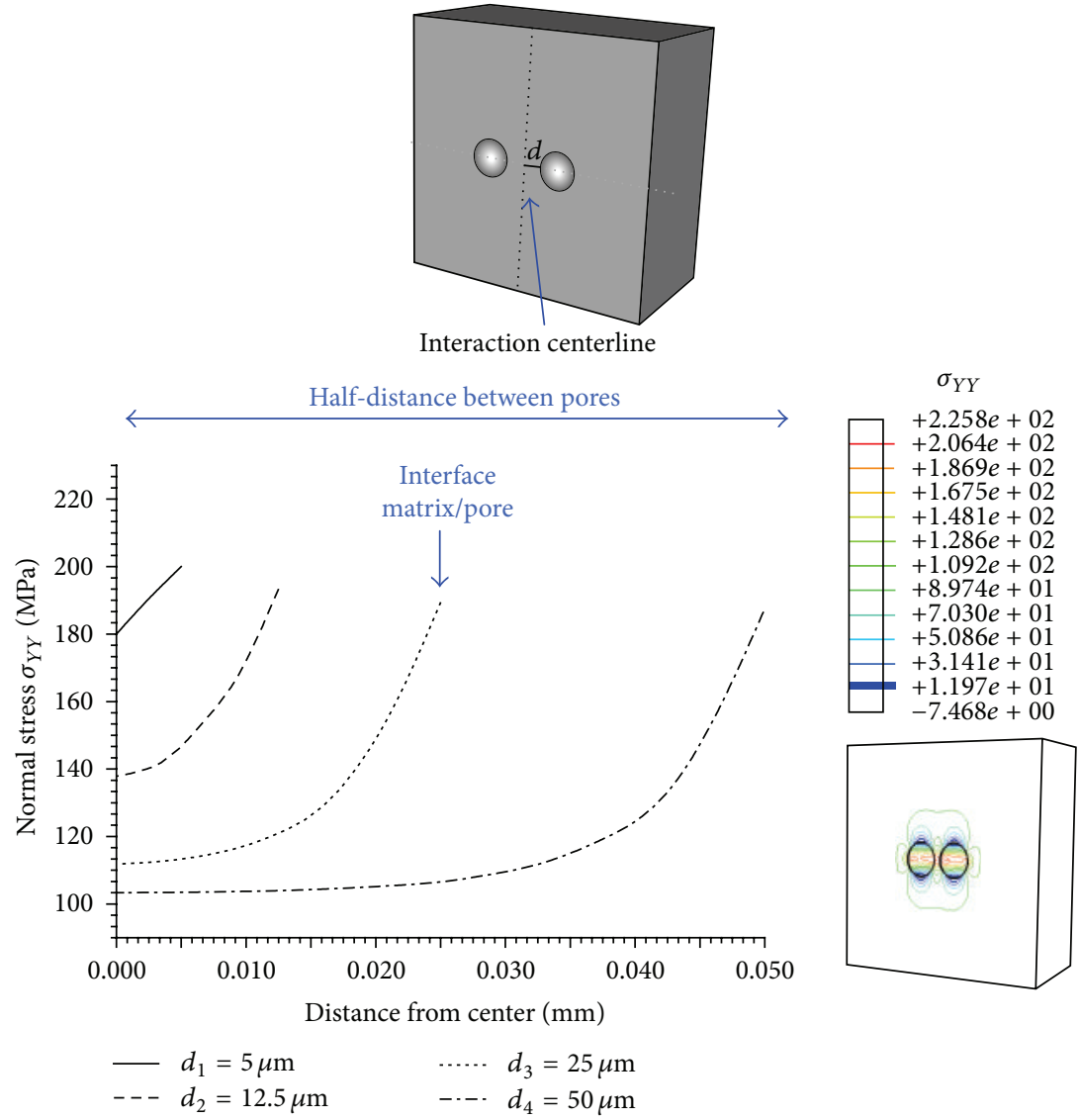

FIgURE 10: Variation of normal stress as functions of the distance from the model's center: cases of two pores, for $P=100 \mathrm{MPa}$ [11].

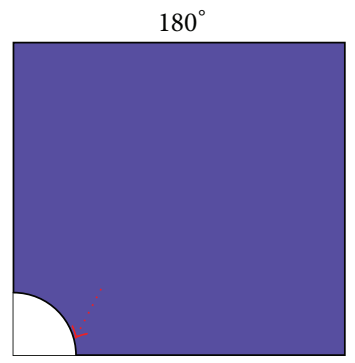

(a)
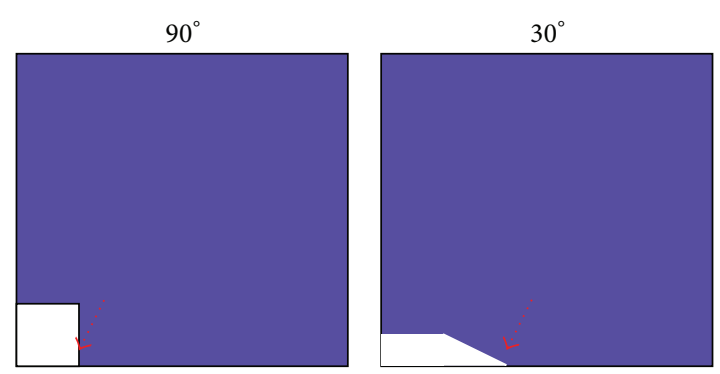

Pointed corner degree of pore

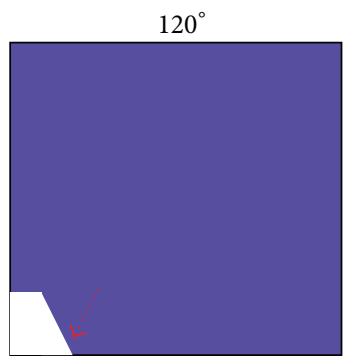

(b)

$30^{\circ}$

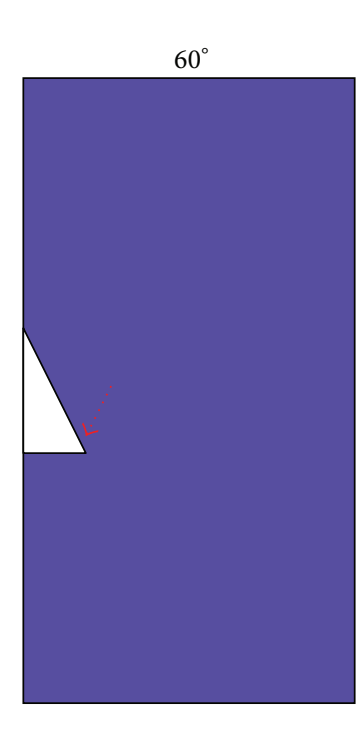

(d)

FIGURE 11: A 2D schematic view of FEM model: (a) spherical pore; (b) hexagon pore; (c) square pore; (d) triangle pore; (e) shuttle-shaped pore. 


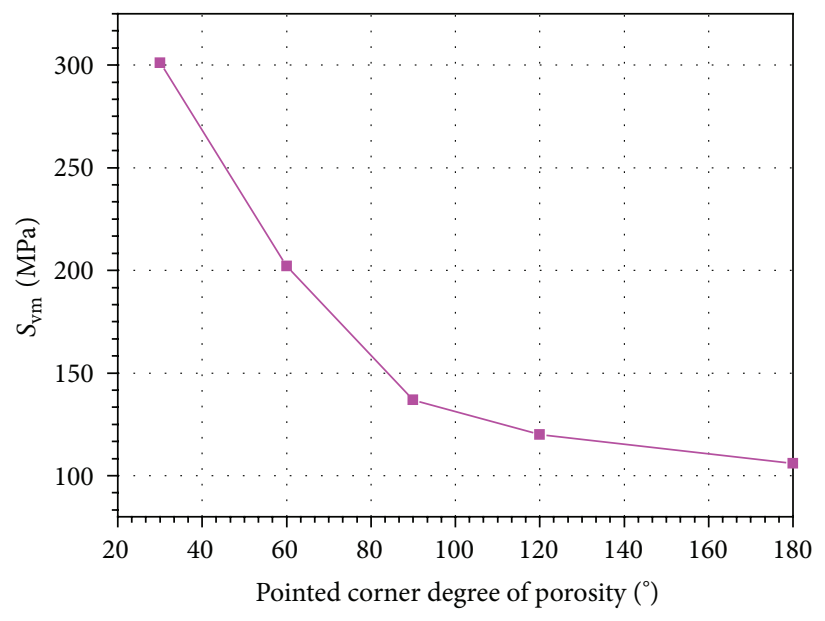

(a)

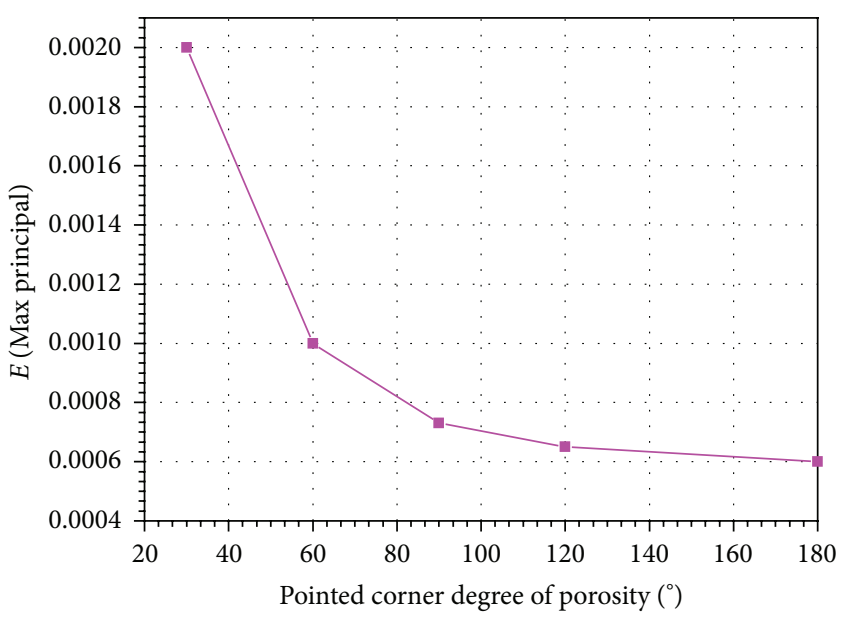

(b)

FIgURE 12: Variation of equivalent stress and Max principal strain $(E)$ according to the pointed corner degree of pore, for $P=70 \mathrm{MPa}$.

\section{List of Symbols}

\author{
$\varphi$ : $\quad$ Diameter of porosity $(\mu \mathrm{m})$ \\ E: $\quad$ Young modulus $(\mathrm{GPa})$ \\ $v$ : Poisson coefficient. \\ $P$ : Tensile mechanical load (MPa) \\ $S_{\mathrm{vm}}$ : von Mises stress $(\mathrm{MPa})$ \\ $S_{22}$ : Normal stress along $y$-axis $(\mathrm{MPa})$ \\ $\theta: \quad$ Peripheral angle $\left(^{\circ}\right)$ \\ $S: \quad$ Max principal stress (MPa) \\ E: Max principal strain $(\mathrm{MPa})$.
}

\section{Conflict of Interests}

The authors declare that there is no conflict of interests regarding the publication of this paper.

\section{References}

[1] S. J. Maddox, "Applying fitness-for purpose concepts to the fatigue assessment of welded joints," in Proceesings of the International Conference on Fatigue, vol. 1, pp. 72-81, Toronto, Canada, 1994.

[2] W. Fricke, "Fatigue analysis of welded joints: state of development," Marine Structures, vol. 16, no. 3, pp. 185-200, 2003.

[3] Y. Zhang and D. Taylor, "Sheet thickness effect of spot welds based on crack propagation," Engineering Fracture Mechanics, vol. 67, no. 1, pp. 55-63, 2000.

[4] H. Kang, M. E. Barkey, and Y. Lee, "Evaluation of multiaxial spot weld fatigue parameters for proportional loading," International Journal of Fatigue, vol. 22, no. 8, pp. 691-702, 2000.

[5] J. M. Barsom, "Fracture mechanics analysis of fatigue crack initiation and growth," in Proceedings of the International Conference on Fatigue, pp. 88-98, Toronto, Canada, 1994.

[6] Y. Sumi and T. Inoue, "Multi-scale modeling of fatigue crack propagation applied to random sequence of clustered loading," Marine Structures, vol. 24, no. 2, pp. 117-131, 2011.

[7] E. E. Gdoutos, Fracture Mechanics: An Introduction, vol. 14 of Solid Mechanics and Its Applications, Springer, 1993.
[8] S. Liu, A. M. Pope, and R. Daemen, "Welding consumables and weldability," in Proceedings of the International Workshop on Underwater Welding of Marine Structures, pp. 321-350, New Orleans, La, USA, December 1994.

[9] F. Bouafia, S. Boualem, M. M. E. Amin, and B. Benali, “3-D finite element analysis of stress concentration factor in spotwelded joints of steel: the effect of process-induced porosity," Computational Materials Science, vol. 50, no. 4, pp. 1455-1464, 2011.

[10] ABAQUS, User's Manual, 6. 5, Hibbit, Karlsson \& Sorensen.

[11] F. Bouafia, B. Serier, B. Boutabout, and B. A. B. Bouiadjra, "Numerical analysis of the effect of pore on local stresses in spot welds," Computational Materials Science, vol. 50, no. 8, pp. 25172529, 2011. 

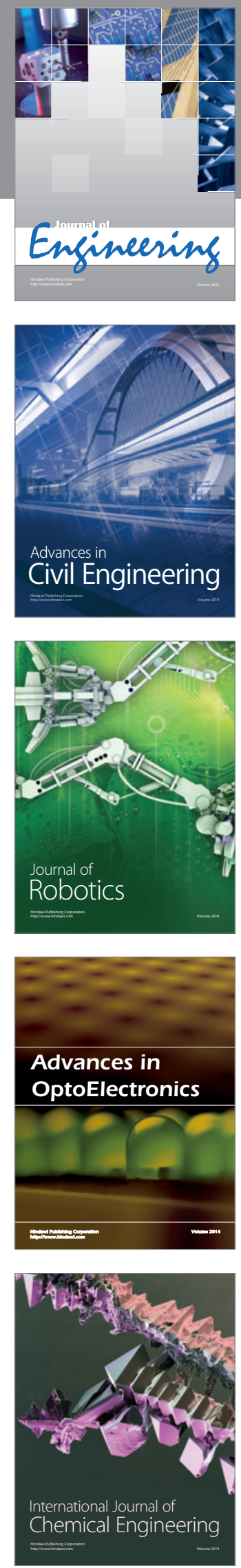

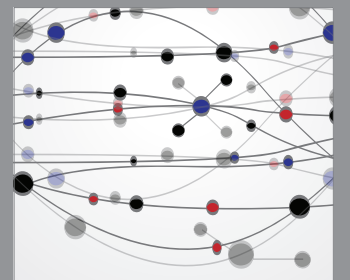

The Scientific World Journal
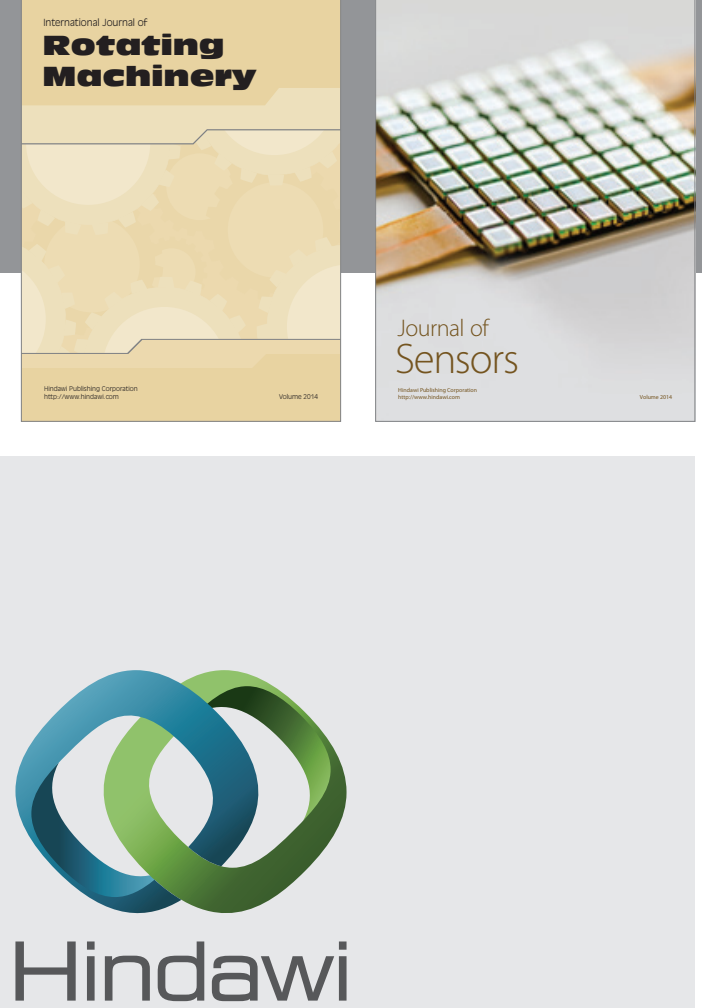

Submit your manuscripts at http://www.hindawi.com
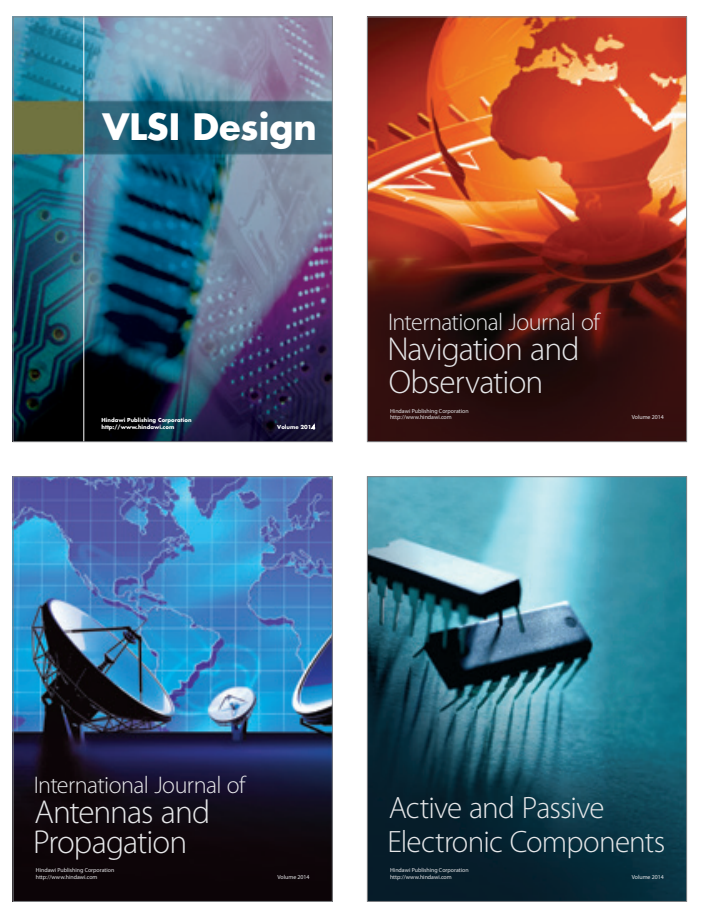
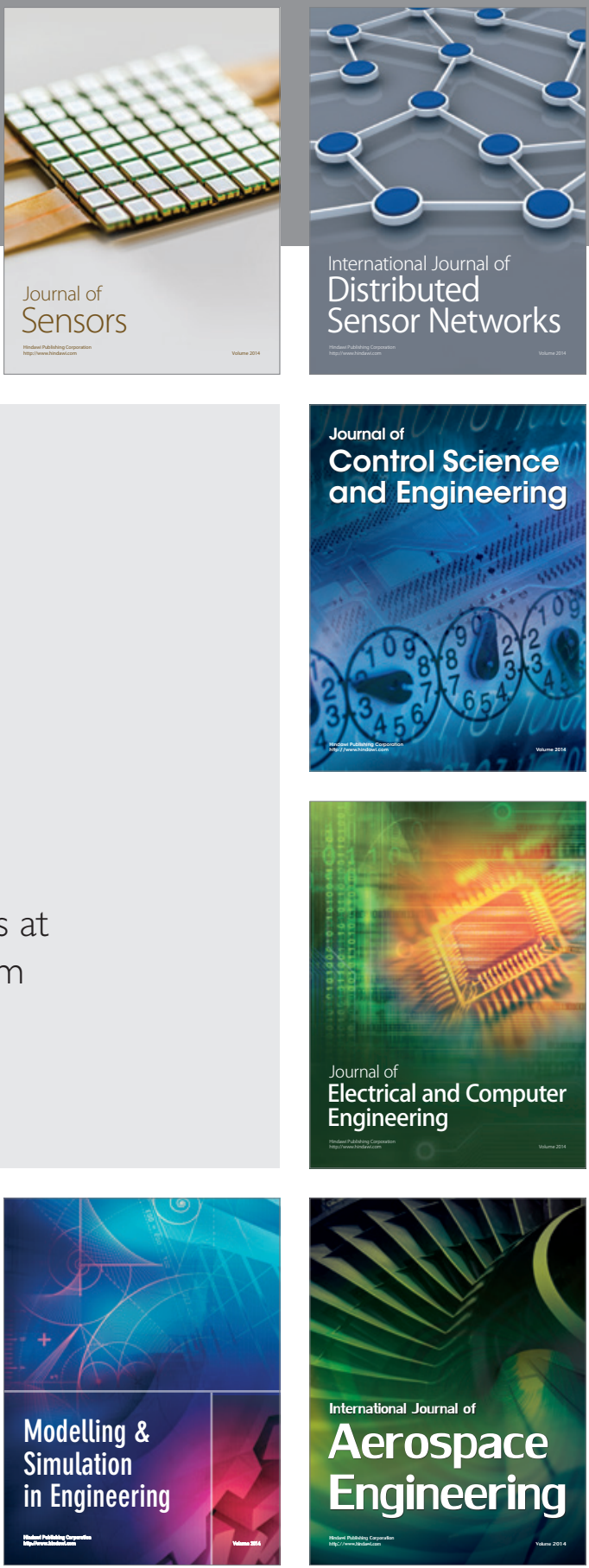

Journal of

Control Science

and Engineering
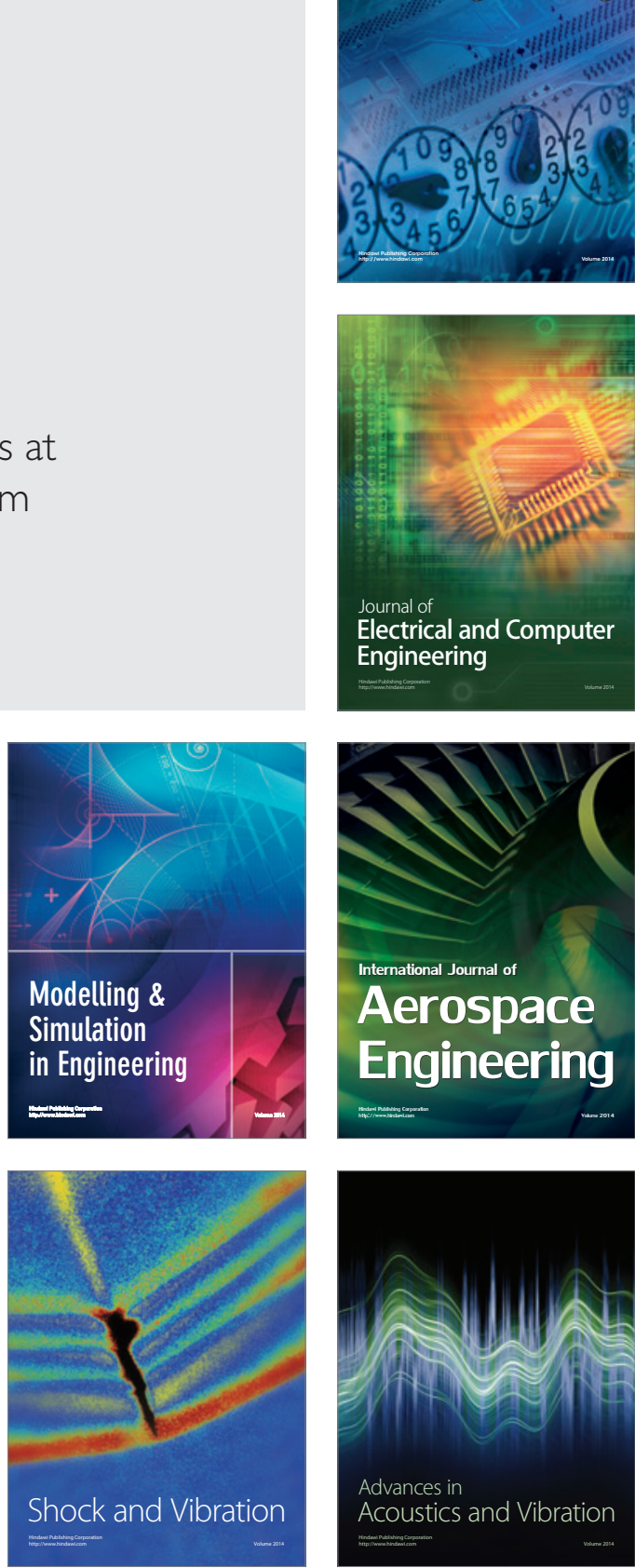